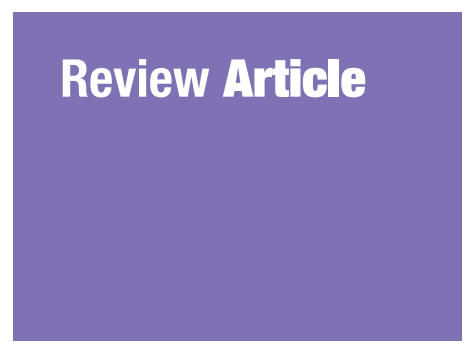

Submitted: 20 Mar 2019

Accepted: 21 Jun 2019

Online: 30 Dec 2019

\section{A Review of Quercus infectoria (Olivier) Galls as a Resource for Anti-parasitic Agents: In Vitro and In Vivo Studies}

\author{
Nik Nor Imam Nik Mat Zin, Wan Nur Addiena WAN Mohd Rahimi, \\ Nurhidanatasha ABU BAKAR
}

School of Health Sciences, Universiti Sains Malaysia, Kubang Kerian, Kelantan, Malaysia

To cite this article: Nik Mat Zin NNI, Wan Mohd Rahimi WNA, Abu Bakar N. A review of Quercus infectoria (Olivier) galls as a resource for anti-parasitic agents: in vitro and in vivo studies. Malays $J$ Med Sci. 2019;26(6):19-34. https://doi.org/10.21315/mjms2019.26.6.3

To link to this article: https://doi.org/10.21315/mjms2019.26.6.3

\begin{abstract}
Parasitic diseases represent one of the causes for significant global economic, environmental and public health impacts. The efficacy of currently available anti-parasitic drugs has been threatened by the emergence of single drug- or multidrug-resistant parasite populations, vector threats and high cost of drug development. Therefore, the discovery of more potent anti-parasitic drugs coming from medicinal plants such as Quercus infectoria is seen as a major approach to tackle the problem. A systematic review was conducted to assess the efficacy of $Q$. infectoria in treating parasitic diseases both in vitro and in vivo due to the lack of such reviews on the anti-parasitic activities of this plant. This review consisted of intensive searches from three databases including PubMed, Science Direct and Scopus. Articles were selected throughout the years, limited to English language and fully documented. A total of 454 potential articles were identified, but only four articles were accepted to be evaluated based on inclusion and exclusion criteria. Although there were insufficient pieces of evidence to account for the efficacy of $Q$. infectoria against the parasites, this plant appears to have anti-leishmanial, anti-blastocystis and anti-amoebic activities. More studies in vitro and in vivo are warranted to further validate the anti-parasitic efficacy of $Q$. infectoria.
\end{abstract}

Keywords: Quercus infectoria, anti-parasitic activity, phytochemicals, toxicity activity, anti-oxidant activity

\section{Introduction}

Parasites exist in two different forms, the unicellular protozoa and the multicellular metazoa that acquire nourishment and other basic needs from their hosts through parasitism. Most parasites reproduce asexually and sexually in a single host species (monoxenous life cycle), while the other parasites reproduce in multiple host species (heteroxenous life cycle) assisted by a living carrier called vector (1). Three major classes of parasites known to cause diseases in humans are protozoa (kingdom Protista), helminths and arthropods (kingdom Metazoa) (2).
Malaria, the most common parasitic disease caused by Plasmodium species affects many lives and caused 435,000 deaths worldwide in 2017 (3). Lymphatic filariasis, soil-transmitted helminthiasis, schistosomiasis, trachoma and/ or onchocerciasis, which are known as neglected tropical diseases (NTDs) caused 1.6 billion deaths in 2015 (4). Many parasitic zoonoses such as cryptosporidiosis, toxoplasmosis and leishmaniasis also result in varying morbidity and mortality among vulnerable populations as well as people suffering from clinical symptoms (i.e. various forms of immunosuppression rather than immunocompetence) (5-7). Entamoeba histolytica, a major pathogen from a group of 
Amebae (protozoa) induces amoebic dysentery and liver abscess that mainly affects areas with poor sanitation, typically through faecalcontaminated water or food (8).

Parasites have unique characteristics whereby parasite-host interactions can be easily accessible due to the similarities in most molecular and biochemical properties $(9,10)$. Hence, it is not surprising that parasites could easily adapt in human hosts for many years and thus, being responsible for parasitic diseases (11). The evolution of parasite mutation through antigenic profile changes and immune evasion mechanisms also increases parasite survival from the host's defence mechanism, leading to life-threatening diseases (12). Chemotherapy remains central to both clinical treatment and disease control whereby the efficacy has constantly been threatened by the emergence of a single drug- or multidrug-resistant parasite populations (12). Other strategies include the development of newly modified former drugs with novel mechanisms to avoid cross-resistance with existing less potent drugs have also been hindered by the challenges of environmental implications as well as vector threats (13). The high expenditure on the development of novel anti-parasitic drugs is another challenge preventing future treatment and control of many parasitic diseases to flourish (14).

The discovery of natural products derived from living organisms such as microorganisms and plants has become one of the major approaches to tackle the parasitic problem (15, 16). The discovery of moxidectin and artemisinin as effective modern medicines is a remarkable example of the therapeutic value derived from natural products first used traditionally (16). Moxidectin and avermectins isolated from a soil bacterium Streptomyces avermitilis have been approved to treat river blindness effectively, which is one of the NTDs transmitted by the bite of blackflies (2). Previously, the active ingredient quinine from the bark of the Cinchona tree was used for the treatment of malaria (17). Currently, artemisinin has been established as a highly potent anti-malarial drug, which is coformulated with other partner drugs to be used as the first-line of treatment for P. falciparum malaria (18). Other bioactive constituents from higher plants such as alkaloids, terpenes and phenolics have also been tested extensively against various parasites and have shown to be potential new drug leads and may have positive impacts on future drug developments (19).
Q. infectoria Olivier (family Fagaceae), a plant of about two metres high, is widely distributed across the Mediterranean area (Greece, Asia Minor, Syria and Iran) (20). Galls from this plant are a special natural product resulting from a parasitic interaction between the plant and the insect known as a gallfly or Cynips gallae-tinctoriae (20). The galls, known as 'manjakani' in Malaysia and 'majuphal' or 'machakai' in India, have been used for ages as a traditional medicine to treat various ailments. Until today, the $Q$. infectoria galls have been utilised by Malay women for post-partum medication and as health supplements (jamu). Some also claimed that the oral administration of jamu from the galls helps to improve blood flow, speed up the contraction of the uterus and tighten the vagina, as well as encourage bowel movement (21). Besides, the galls have also been used in Thailand traditional medicine for treating stomach ache $(22,23)$ while in India, the galls extract has been used for oral care as mouth wash, dental powders and for treatment of toothache $(24,25)$. The galls are rich with tannins, the phenolic compounds, which are thought to have an astringent effect and have also been used in topical therapies for skin lesions and inflammation in Chinese medicinal herb (24).

The medicinal values of $Q$. infectoria with anti-diabetic (26), anti-tremorine (27), antiinflammatory (28) and astringent activities (25), as well as having a broad spectrum of antimicrobial properties such as anti-bacterial (2931), anti-viral (32) and anti-fungal activities (33, 34) have been highlighted as the outstanding potentials of the galls. The diverse antimicroorganism activities of $Q$. infectoria galls have encouraged researchers to further study the biological activities of the plant. This present work is a review of information on the antiparasitic activities of $Q$. infectoria galls in vitro and in vivo that could be used by researchers to comprehensively investigate the molecular mechanisms underlying the anti-parasitic effects of the galls.

\section{Methods}

\section{Search Strategy}

Three electronic databases used as sources for literature review were PubMed, Science Direct and Scopus from 1990 until 7 January 2019. As the purpose of this review 
was to systematically evaluate the efficacy of $Q$. infectoria galls in treating parasitic diseases, research articles conducted in vitro, in vivo or both were targeted.

The keywords used as the search terms were as follows:

i. Quercus infectoria and anti-microbial

ii. Quercus infectoria and anti-parasitic

iii. Quercus infectoria and anti-protozoal

iv. Quercus infectoria and anti-leishmanial

v. Quercus infectoria and anti-helminthic

vi. Quercus infectoria and anti-malarial

vii. Quercus infectoria and anti-amoebic

viii. Quercus infectoria and anti-blastocystis

ix. Quercus infectoria and anti-plasmodial

x. Quercus infectoria and anti-trypanosomal

xi. Quercus infectoria and anti-giardial

xii. Quercus infectoria and anti-schistosomial

xiii. Quercus infectoria and anti-acanthamoeba

\section{Research Article Selection and Evaluation}

Search results were limited to fully documented articles in English without restriction on the date of publication.

Inclusion criteria:

i. Full-text articles

ii. In vitro studies related to parasites

iii. In vivo studies related to parasites

iv. Intervention subject, with only Quercus infectoria

Exclusion criteria:

i. Irrelevant titles and abstracts

ii. Duplicated studies

iii. Reviews

iv. Subject index

v. News

vi. Case studies

vii. Poor methodology

viii. Not related to any parasites

Two independent reviewers screened the articles based on the inclusion and exclusion criteria stated above. For the first screening, the related articles were screened based on their titles and abstracts. Next, the remaining papers were checked for duplications and those with exclusion criteria were also eliminated. Finally, the selected full-text articles were checked by another reviewer according to the inclusion criteria for final validation. The extracted data are summarised as shown in Table 1, Table 2, Table 3 and Table 4.

\section{Results and Discussion}

\section{Summary of Included Studies}

A total of 454 potential articles were obtained using keyword search from PubMed, Science Direct and Scopus databases. A total of 139 duplicates were removed. From the remaining 315 articles, five articles were selected after those potentially not related to the criteria including irrelevant titles and abstracts, reviews, subject index, news and case studies were removed. Finally, four full-text articles, which fulfilled the inclusion and exclusion criteria were accepted after further evaluation of the five articles. Figure 1 illustrates the article selection based on the inclusion and exclusion criteria.

Of the four selected articles, five antiparasitic studies conducted consist of three in vitro and two in vivo studies and appeared in the literature between 2004 and 2016. Two of the four articles were conducted in Southeast Asia (Thailand), while the remaining two articles were conducted in Middle East countries (Turkey and Iran) (Table 1). All of the articles reported the use of methanol as a solvent for plant extraction, and two articles reported the use of other solvents such as n-hexane $(23,35)$ and dichloromethane (23). Nevertheless, the in vitro anti-oxidant and toxicity studies presented in the selected articles were also included in this review to support the efficacies and the anti-parasitic activities of Q. infectoria.

A total of three in vitro anti-parasitic studies were conducted by Sawangjaroen and Sawangjaroen (23), Ozbilgin et al. (35) and Kheirandish et al. (36), while two in vivo studies were carried out by Sawangjaroen et al. (37) and Kheirandish et al. (36) (Table 4). Three types of parasites were subjected to the studies: Entamoeba histolytica (37), Blastocystis hominis and Blastocystis spp $(23,35)$ and Leishmania major (36). For the in vivo studies, mice models were exclusively used, specifically female Swiss albino mice and male BALB/c mice. 


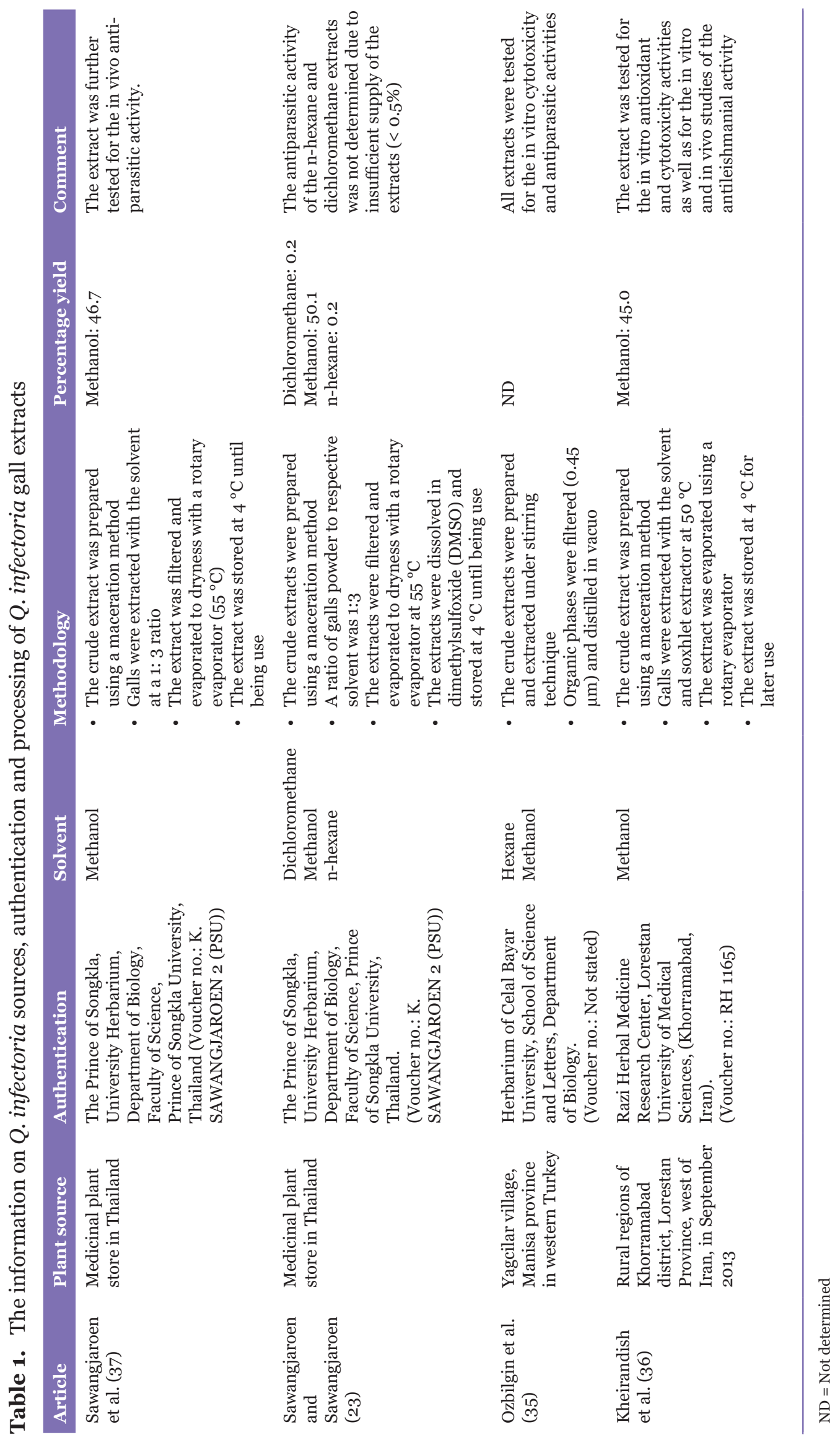


Review Article | Quercus infectoria as anti-parasitic agents

Table 2. The secondary metabolites in the methanol extract of Q. infectoria galls

\begin{tabular}{lcc} 
Article & Chemical constituents & Percentage of yield \\
Kheirandish et al. (36) & Phenolic & 57.5000 \\
& Flavonoid & 1.8600 \\
Quercetin & 0.0064 \\
Gallic acid & 0.2200 \\
\hline
\end{tabular}

Table 3. The summary of the anti-oxidant and toxicity effects of different $Q$. infectoria solvents on the brine shrimps test and cytotoxicity assay

\begin{tabular}{|c|c|c|c|c|c|}
\hline \multirow[b]{2}{*}{ Article } & \multirow[b]{2}{*}{ Extract } & $\begin{array}{l}\text { Antioxidant } \\
\text { activity }\end{array}$ & \multicolumn{2}{|c|}{ Toxicity effects } & \multirow[b]{2}{*}{ Interpretation } \\
\hline & & $\begin{array}{c}\mathrm{IC}_{50} \\
(\mu \mathrm{g} / \mathrm{mL})\end{array}$ & $\begin{array}{c}\text { BSLT test } \\
\text { LC }_{50} \\
(\mu \mathrm{g} / \mathrm{mL})\end{array}$ & $\begin{array}{c}\text { MTT assay } \\
\text { CC }_{50} \\
(\mu \mathrm{g} / \mathrm{mL})\end{array}$ & \\
\hline
\end{tabular}

Ozbilgin et al. Methanol ND $\quad$ NDO.86 ND The extract was considered as toxic (35)

\begin{tabular}{|c|c|c|c|c|c|}
\hline & n-hexane & ND & $\begin{array}{l}\text { NR (non- } \\
\text { toxic) }\end{array}$ & ND & $\begin{array}{l}\text { No value for } \mathrm{LC}_{50} \text { for the extract } \\
\text { was shown. However, no toxicity } \\
\text { was reported for the extract in the } \\
\text { article }\end{array}$ \\
\hline $\begin{array}{l}\text { Kheirandish } \\
\text { et al. (36) }\end{array}$ & Methanol & 30.78 & ND & 210.755 .18 & $\begin{array}{l}\text { The extract showed a considerable } \\
\text { antioxidative activity and not } \\
\text { significant when compared with } \\
\text { the positive control [butyl hydroxy } \\
\text { tuloene (BHT) standard] which } \\
\text { has an } \mathrm{IC}_{50} \text { value of } 31.50 \mu \mathrm{g} / \mathrm{mL} \\
(P>0.05) \text {. The extract had no } \\
\text { cytotoxic effect on the normal } \\
\text { human macrophage cells }\end{array}$ \\
\hline
\end{tabular}

Notes: $\mathrm{ND}=$ not determined, $\mathrm{NR}=$ not reported

Half maximal inhibitory concentration $\left(\mathrm{IC}_{50}\right.$ ) is the concentration required to inhibit $50 \%$ oxidation (free radical). Half median lethality concentration $\left(\mathrm{LC}_{50}\right)$ is the concentration required for killing $50 \%$ shrimps. Half maximal cytotoxicity concentration $\left(\mathrm{CC}_{50}\right)$ is the concentration required for being toxic to the cells at $50 \%$

\section{Preliminary Phytochemical Analysis of the Crude Extracts of the Q. infectoria Galls}

The activities of the plant could be influenced by various factors such as the plant species and the parts of the plant, sex of cultivars, geographical origin, harvesting time as well as climatic conditions which can also interrupt the reproducibility of the results (38). As the demand for herbal medicines increases due to minimal adverse effects seen in humans compared to synthetic drugs (39), it is necessary to characterise herbal medicines to ensure their quality, efficacy and safety. To verify and ensure that the correct plant was assessed throughout this review, it is crucial for the plant in the selected articles to be authenticated. This is because the sources of medicinal plants may vary according to the respective countries (39). In this review, all four studies reported the authentication of $Q$. infectoria galls with the voucher specimen that was made in their respective countries (Thailand, Turkey and Iran) (23, 35-37) (Table 1).

From the four selected articles, a total of three solvents (methanol, n-hexane and dichloromethane) were used and the percentage yield of the extracts of $Q$. infectoria galls was identified as indicated in Table 1. Briefly, a conventional maceration method was carried 

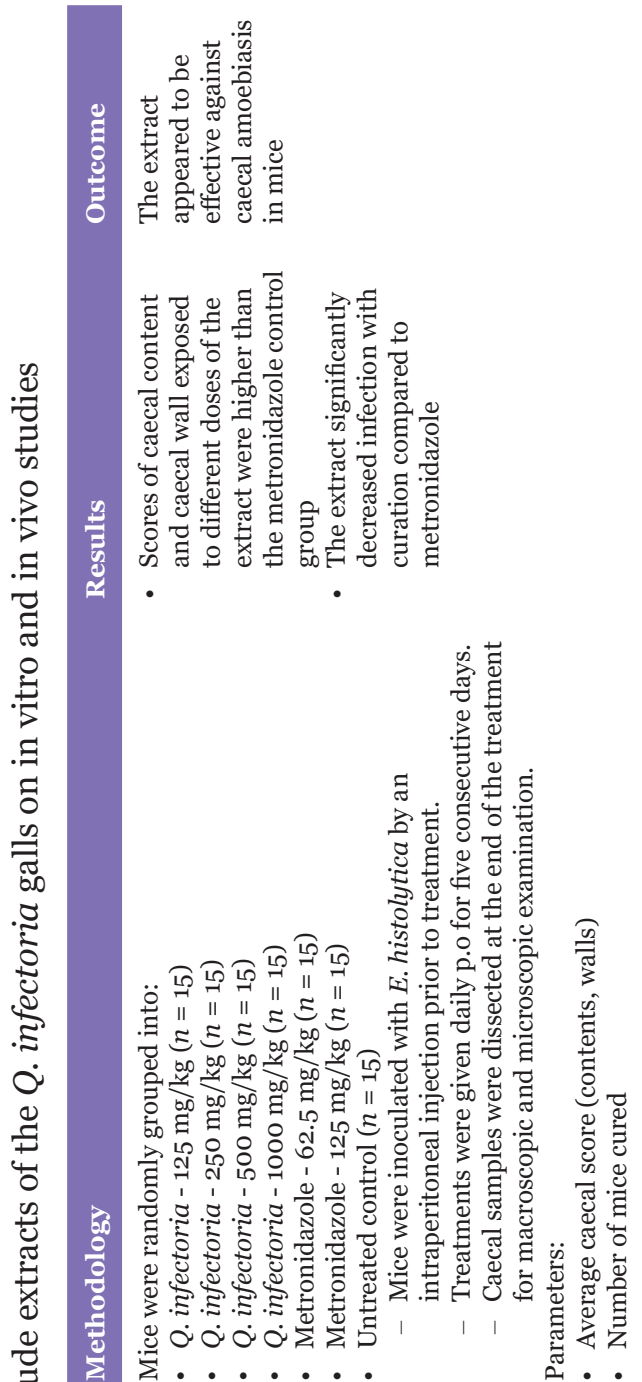

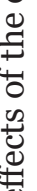

$:$

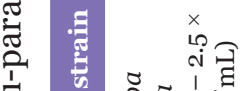

.

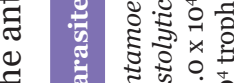

4

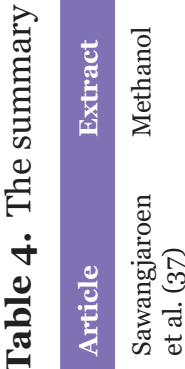

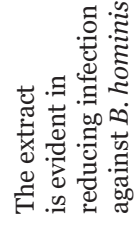

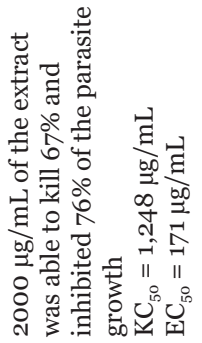

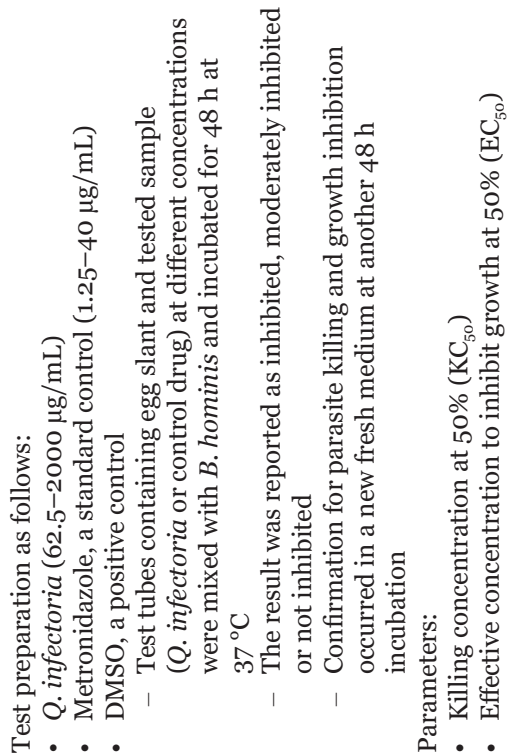

$\stackrel{\circ}{5}$
$\Xi$

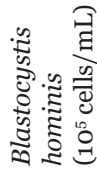

宊

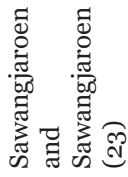


Review Article | Quercus infectoria as anti-parasitic agents

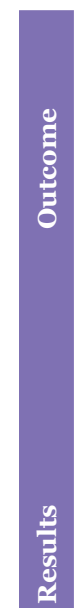

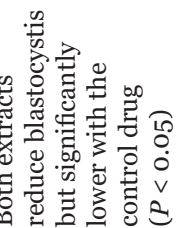

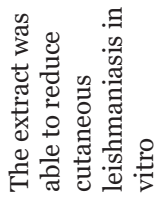

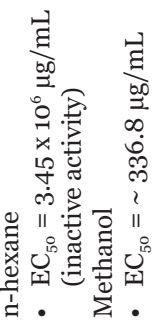

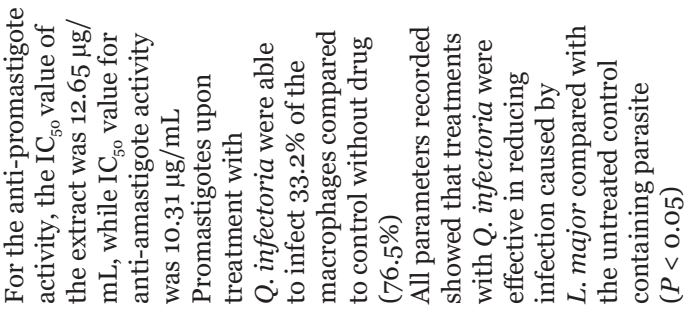

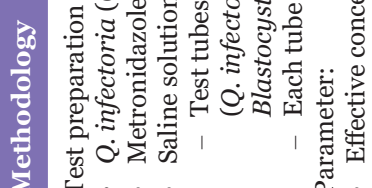
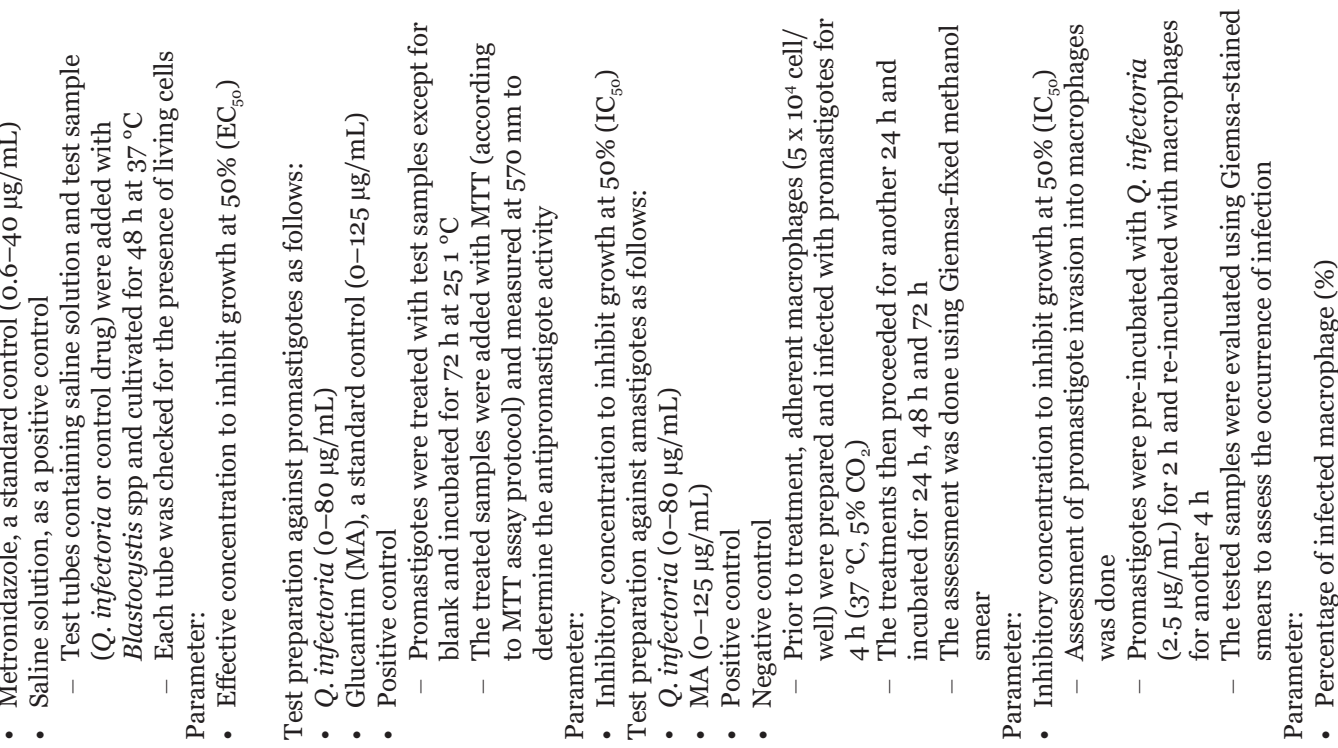

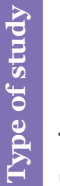

章

$\stackrel{8}{5}$

ह

호을

2.

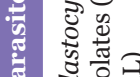

:

है

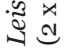

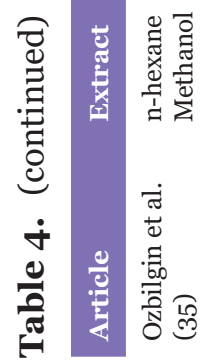

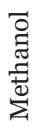

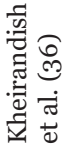




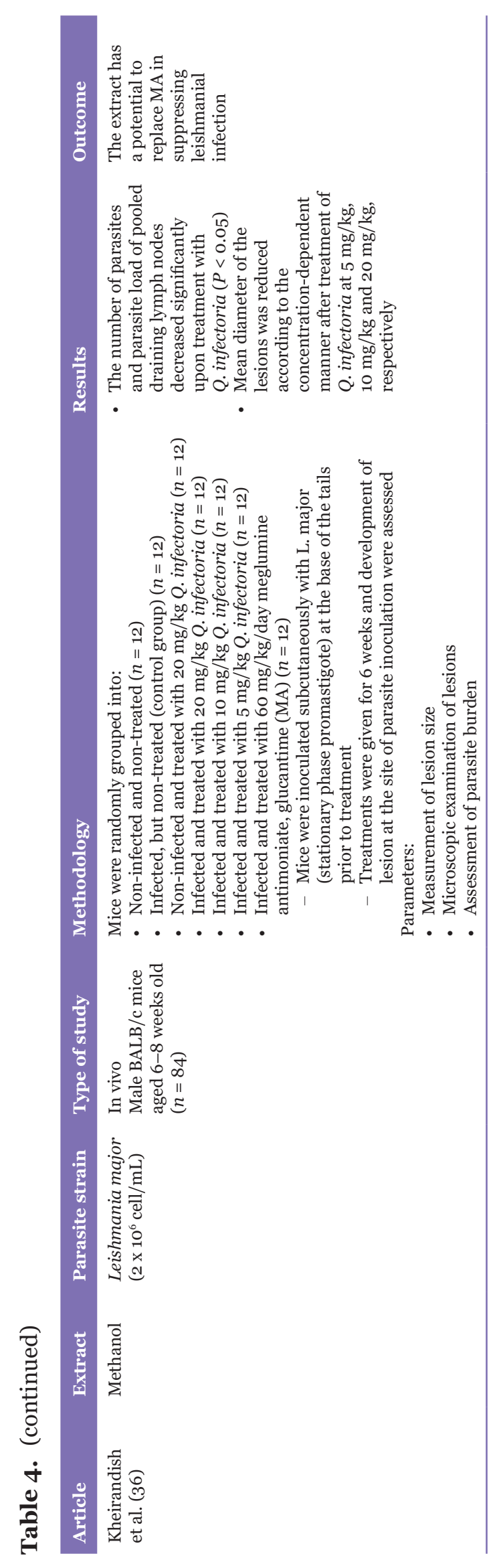


Review Article | Quercus infectoria as anti-parasitic agents

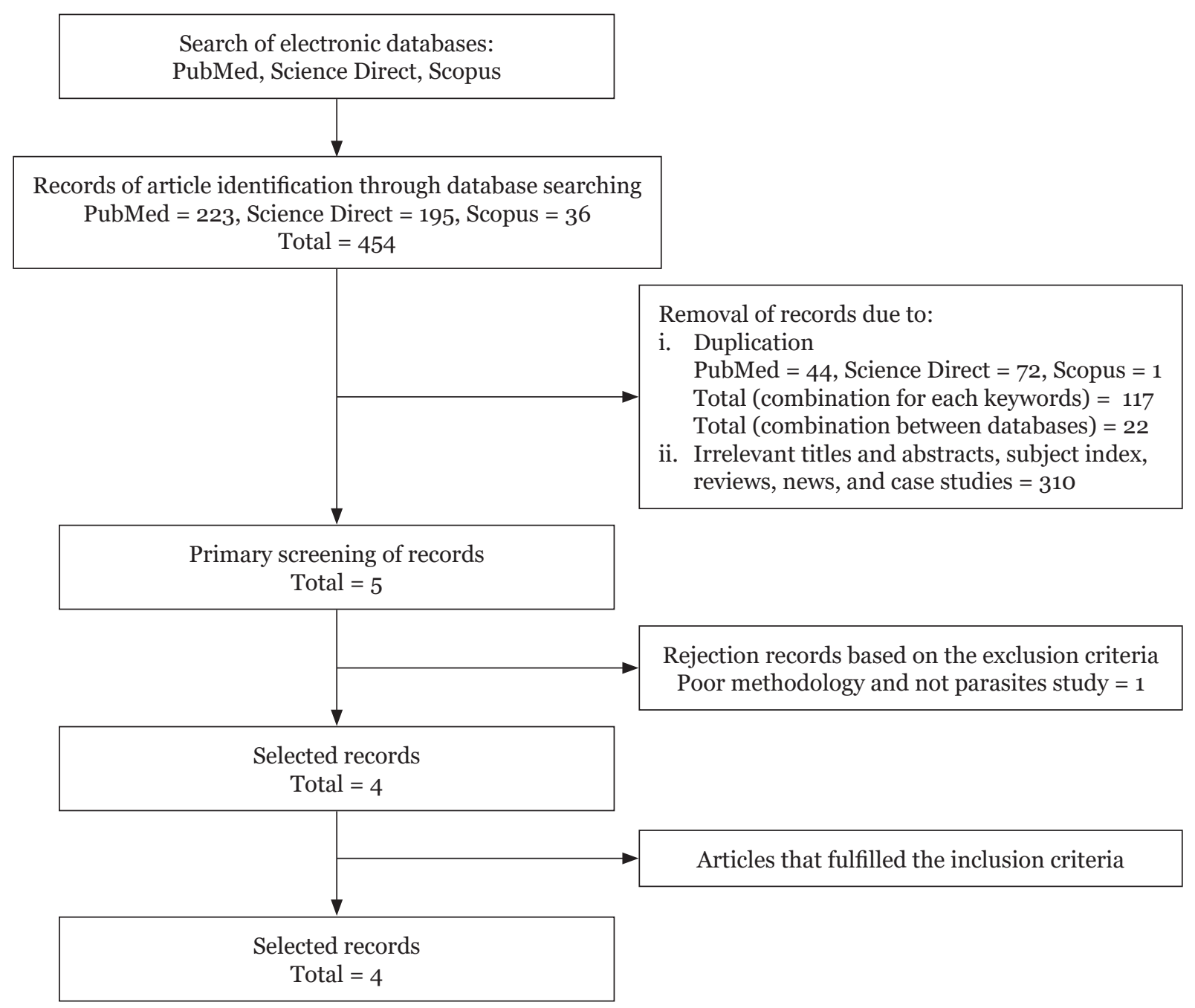

Figure 1. The selection process of the articles used in this systematic review

out where $Q$. infectoria galls were extracted at an appropriate ratio (1:3) of gall powder to solvent, filtered and evaporated to dryness to form powdery extracts. The methanol extract was tested in all of the selected articles. This extract represented the highest yield at $50.1 \%$, $46.7 \%$ and $45.0 \%$ in three out of four articles (23, $36,37)$. The percentage yield recorded for the methanol extract has no significant difference between all studies, indicating that the extraction method does not influence the total crudes obtained $(P>0.05)$ (40).

Phytochemical composition of plant sources is the primary identification for the fundamental understanding of the acting mechanism of the crude extracts (41). Unlike primary metabolites, which are required for maintaining growth as well as proliferation, secondary metabolites (also known as bioactive metabolites) not only function as a protectant under damage due to stress and harsh environment, but also serve as a weapon against several microorganisms such as bacteria, fungi, parasite and higher organisms (42). A study by Kheirandish et al. (36) was conducted to determine the bioactive compounds in the $Q$. infectoria methanol extract before the anti-leishmanial test. Determination of the total percentage of phenolic and flavonoid compounds was carried out using FolinCiocalteau and Dowd methods, respectively. Quercetin and gallic acid were also analysed using high performance liquid chromatography (HPLC). The results showed that both phenolic and flavonoid compounds exist in the methanol extract, however, in comparison, the presence of the phenolic compound (57.50\%) is higher than the flavonoid $(1.86 \%)$ in the methanol extract (Table 2). The values of quercetin and gallic acid were $0.0064 \%$ and $0.22 \%$, respectively (Table 2 ). A similar study conducted by Baharuddin et al. 
(33) also showed that the presence of phenolic compound in both methanol and aqueous extracts of $Q$. infectoria galls using GC-mass spectrophotometry (GC-MS) analysis, thus proves that the main compounds in the methanol extract of $Q$. infectoria galls were the phenolic compound (expressed as $0.22 \%$ of gallic acid) followed by flavonoid (expressed as $0.0064 \%$ quercetin).

The main bioactive constituent found in both methanol and aqueous extracts of Q. infectoria galls was pyrogallol or hydrolysable tannin from phenolic compound (33). Pyrogallol is known to be associated with many biological activities and implicated in many anti-microbial activities such as anti-bacterial, anti-candidicidal and anti-fungicidal (43). Interestingly, Abdullah et al. (44) recently revealed that different semi purifed fractions of the aqueous extract of $Q$. infectoria have similar polyphenolic compositions such as gallic acid and digallate as well as ellagic acid, syringic acid and theogallin, which have also been detected using liquid chromatography mass spectrometry (LC-MS), implying the richness of phenolic compounds in the galls. Similarly, ethanol extract of Q. infectoria galls has also been shown for their high content of phenolic compounds such as p-Hydroxybenzoic, pyrogallol, catechol, caffeine and gallic acid (31). Flavonoid compound found in the ethanol extract with the main flavonoid compound was naringin, rutin, rosmarinic, quercetrin and quercetin (31). Taken together, the above studies suggest that the anti-parasitic activities of the $Q$. infectoria gall extracts could be mediated through the presence of rich contents of phenolic and flavonoid compounds.

\section{Screening of Toxicity and Anti-Oxidant Activities of $Q$. infectoria}

Scientific evidence to establish the safety of herbal medicines for human consumption is important to assure consumers of unwanted side effects (45). There are two methods used for toxicity testing of the extracts of $Q$. infectoria galls found in the chosen articles (Table 3): brine shrimp lethality test (BSLT) and cytotoxicity test. The BSLT test carried out by Ozbilgin and his colleagues (35) showed that the $\mathrm{LC}_{50}$ value (a lethal concentration that kills 50\% of the shrimp population) of the methanol extract was considered as toxic according to Meyer's toxicity index (46). However, the n-hexane extract was reported as non-toxic even though the $\mathrm{LC}_{50}$ value of the extract was not indicated in the study.
In the study by Kheirandish et al. (36), the methanol extract of the galls was assessed for both cytotoxicity and anti-oxidant activities. The extract was considered to possess a promising anti-oxidant activity with an $\mathrm{IC}_{50}$ value (a concentration that inhibits oxidation by $50 \%$ ) of $30.78 \mu \mathrm{g} / \mathrm{mL}$ while butyl hydroxy toluene (BHT) (a standard anti-oxidative agent) gave an $\mathrm{IC}_{50}$ value of $31.50 \mu \mathrm{g} / \mathrm{mL}$ (Table 3). The finding was supported by the high percentage of phenolic and flavonoid compounds in the methanol extract, which enhanced antioxidant activity by trapping, scavenging and eliminating free radicals and by chelating metals $(47,48)$. The cytotoxicity activity of the extract on macrophage cells was also evaluated using 3-(4,5-dimethylthiazol-2-yl)-2,5diphenyltetrazolium bromide (MTT) assay (36). The $\mathrm{CC}_{50}$ value (a concentration that reduces cell viability by 50\%) shows no cytotoxic effect of the extract on the normal macrophage cells.

The contradictory results obtained from the BSLT and cytotoxicity tests of the methanol extract might be due to the differences of the in vitro models (i.e. shrimps and normal human macrophage cells), concentrations of the plant extract, and geographical origin of the plant sources that were used in the two studies (45).

\section{Anti-Parasitic Activities of the Crude Extracts of the Quercus infectoria Galls Against Intestinal and Intracellular Protozoa}

A total of four articles consisting of three in vitro and two in vivo studies conducted between 2004 and 2016 were examined for the effects of the crude extracts of $Q$. infectoria galls against the parasites. The three in vitro studies were conducted by Sawangjaroen and Sawangjaroen (23), Ozbilgin et al. (35) and Kheirandish et al. (36), while two in vivo studies were carried out by Sawangjaroen et al. (37) and Kheirandish et al. (36).

The study of the $Q$. infectoria methanol extract on caecal amoebiasis-infected mice was conducted by Sawangjaroen et al. (37) using Entamoeba histolytica, an intestinal pathogenic protozoan isolated from the infected patient at Maharaj Hospital, Nakorn Srithamarat, Thailand (Table 4). This experiment was the first to use a mice model in contrast to previous studies, which generally utilised rat models in anti-amoebic tests $(37,49)$. They reported that female Swiss albino mice fed with $500 \mathrm{mg} / \mathrm{kg}$ of the extract showed a higher number of mice 
cured from amoebiasis (26\%) compared to the untreated control group after five consecutive days of treatment. The severity of the mice caecal content and the caecal wall lesions were also reduced in comparison to the untreated mice. Metronidazole was used as a standard control in the experiment (showed 100\% curing of $E$. histolytica-infected mice at $125 \mathrm{mg} / \mathrm{kg}$ ) to compare the performance of the extract against the parasite. Although there was a significant difference in the anti-amoebic activity between the extract and the standard drug $(P<0.05)$, the extract could be said to at least help in reducing severity occurred in the mice intestine. Thus, the researchers concluded that the $Q$. infectoria methanol extract appeared to have an antiamoebic potential against caecal amoebiasis in mice.

Blastocystis spp. (e.g. B. hominis) is a common protozoan detected in the human intestine and primarily recognised as a normal intestinal flora but can result in diarrhoea, abdominal pain and vomiting in immunosuppressed hosts $(50,51)$. Claimed as an alternative for diarrhoea treatment in highrisk countries (52), two in vitro studies were conducted by Sawangjaroen and Sawangjaroen (23) and Ozbilgin et al. (35) using the $Q$. infectoria extracts against different virulent strains of Blastocystis spp. isolates (Table 4). They reported that the inhibitory effects of the extracts were dose-dependent. At 2,000 $\mu \mathrm{g} / \mathrm{mL}$, the methanol extract of the $Q$. infectoria galls evaluated by Sawangjaroen and Sawangjaroen (23) killed 67\% $\left(\mathrm{KC}_{50}=1248 \mu \mathrm{g} / \mathrm{mL}\right)$ and inhibited $76 \%\left(\mathrm{IC}_{50}=171 \mu \mathrm{g} / \mathrm{mL}\right)$ of $\mathrm{B}$. hominis. Later, Ozbilgin et al. (35) investigated which type of extract (n-hexane and methanol) showed the best performance against the parasite. They showed that the methanol extract was the most effective to inhibit the in vitro growth of Blastocystis spp. isolates $\left(\mathrm{EC}_{50}=\sim 336.8 \mu \mathrm{g} /\right.$ $\mathrm{mL}$ ) compared to the n-hexane extract. From the two studies using the methanol extract, the study done by Sawangjaroen and Sawangjaroen (23) showed the most active methanol extract in comparison to the methanol extract prepared by Ozbilgin et al. (33).

Leishmaniasis is one of the seven most important tropical diseases caused by an obligate intracellular parasite from the genus of Leishmania and transmitted to humans by the bite of the arthropod infected female sand fly, mainly Phlebotomus in the Old World and Lutzomyia in South America (53, 54).
The vector-borne disease is manifested by three clinical forms: visceral, cutaneous and mucocutaneous leishmaniasis (55), whereby cutaneous leishmaniasis (CL) is associated with ulcers, cauliflower-like masses or nodules (56). Therefore, both in vitro and in vivo anti-leishmanial studies were evaluated by Kheirandish et al. (36) against promastigote (the virulent form with flagella) and amastigote forms (non-flagellated) of $L$. major. The in vitro study showed that the amastigote form of $L$. major was more sensitive to the $Q$. infectoria methanol extract compared to the promastigote form. They also reported that the methanol extract demonstrates promising results compared to a reference anti-leishmanial drug, glucantime meglumine antimoniate (MA) in an in vitro study (Table 4). Similar results were obtained in the in vivo study, whereby the number of parasites and parasite load significantly decreased $(P<0.05)$ after treatment with 10 $\mathrm{mg} / \mathrm{kg}$ and $20 \mathrm{mg} / \mathrm{kg}$ of the methanol extract compared to the untreated control group with no decrease in the number of parasites. Moreover, the diameter of the tail lesion affected by L. major also reduced to about $0.86 \mathrm{~cm}, 4.20 \mathrm{~cm}$ and $5.11 \mathrm{~cm}$ from $14.14 \mathrm{~cm}$ (the untreated control size of the lesion) at the concentration of $20 \mathrm{mg} /$ $\mathrm{kg}, 10 \mathrm{mg} / \mathrm{kg}$ and $5 \mathrm{mg} / \mathrm{kg}$ of the extract after four weeks of treatment, respectively. Healing rate of the lesion in infected male BALB/c mice was observed after four weeks of treatment with $20 \mathrm{mg} / \mathrm{kg}$ extract (91.6\% recovery) compared to MA (66.6\%) indicating that the extract was highly potent in reducing leishmaniasis. They presumed that the high amount of phenolic compound $(57.50 \%)$ might be responsible for the anti-leishmanial activity of the extract. Consistent with the previous study, inhibition of $L$. tropica and L. major was correlated with the content of the phenolic compound of Tunisian olive tree (57).

Although the mechanism of anti-parasitic action of $Q$. infectoria has not yet been elucidated, its ability to curb protozoa-causing diseases is thought due to the vast variety of bioactive constituents, which are responsible for the disruption of amino acid production required for parasitic growth during translation pathway (36). The bioactive compounds present have also exhibited an anti-microbial effect by damaging the cell membrane, which also seems to be the mode of anti-parasitic action of $Q$. infectoria (36). 
All in vitro studies from the selected articles showed that $Q$. infectoria has the potential in decreasing the parasite growth evaluated by the $\mathrm{IC}_{50}$ and $\mathrm{EC}_{50}$ values and in killing the parasites based on the $\mathrm{KC}_{50}$ value against blastocystis and leishmaniasis. Furthermore, the in vivo studies also showed similar results in which $Q$. infectoria was able to inhibit parasites causing amoebiasis and leishmaniasis. The findings provide a fundamental view that $Q$. infectoria could be further investigated for searching potential bioactive metabolites responsible for antiparasitic activities such as anti-malarial activity.

\section{Strength and Limitations}

This systematic review is among the first to describe in detail the in vitro and in vivo studies on the efficacy of $Q$. infectoria galls against the parasites. It prioritises the anti-parasitic aspects using the $Q$. infectoria crude extracts whilst various other studies concentrated more on other microorganisms and diseases. Vaccines still do not work for many parasites, causing most parasitic diseases to be neglected. This review has a huge advantage in providing the knowledge gap on the $Q$. infectoria capability, which can be used as a reference for new research to support the efficacy of $Q$. infectoria by elucidating the anti-parasitic activities against several other parasites. This review also identified several limitations. Several studies did not clearly state the proper methodology of the plant extraction (e.g. ratio of gall powder to solvent) and the final percentage of yield obtained, hence restricted future studies to prepare and produce appropriate stocks of the crude extracts. Furthermore, the phytochemical constituents of several extracts had not been revealed qualitatively and quantitatively because different solvents might influence the outcome of the constituents, which might be responsible for the anti-parasitic activity. Moreover, only a few studies identified the toxicity of the plant. It is important to evaluate in detail the safety of $Q$. infectoria galls both in vitro and in vivo before different tests could be carried out and before the plant could be implemented as an alternative, promising and safe anti-parasitic agent. Lastly, some experiments against virulent parasites were only performed in vitro and not in vivo and vice versa, restricting the promising results against the anti-parasitic activity of the plant.

\section{Recommendation}

Based on this review, we suggest more rigorous studies using other different parasites both in vitro and in vivo to support the efficacy of $Q$. infectoria galls. This plant might have activities and effects against many other parasites without compromising the plant status, extraction method, phytochemistry as well as the toxicological aspects to maintain the reproducibility and accuracy of the overall studies.

\section{Conclusion}

There is still insufficient evidence to draw a definitive conclusion on the efficacy of $Q$. infectoria galls against the parasites tested; however, it appears to possess the antileishmanial potential against $L$. major shown in both in vitro and in vivo studies. The plant is also a novel candidate to treat other tropical parasitic diseases such as blastocystis and amoebiasis. Therefore, the available data from the in vitro and in vivo tests might warrant further studies to provide more details and clearer overview of the anti-parasitic properties of the $Q$. infectoria galls.

\section{Acknowledgements}

We would like to thank the School of Health Sciences and the Universiti Sains Malaysia libraries (Perpustakaan Hamdan Tahir and Perpustakaan Hamzah Sendut) for providing the resources to write the systematic review.

\section{Conflict of Interest}

The authors declare to have no conflicts of interests whatsoever. The authors are responsible for the content and the writing of this paper.

\section{Funds}

We would also like to thank Universiti Sains Malaysia for providing the financial support under the USM RUI Grant (1001/PPSK/812201). The first author also receives Graduate Assistant Scheme (2018/2019) from Universiti Sains Malaysia. 
Review Article | Quercus infectoria as anti-parasitic agents

\section{Author's Contributions}

Conception and design: NNINMZ, WNAWMR, NAB

Analysis and interpretation of the data:

NNINMZ, WNAWMR

Drafting of the article: NNINMZ, WNAWMR, NAB

Critical revision of the article for important

intellectual content: NAB

Final approval of the article: NAB

Provision of study materials or patients: $\mathrm{NAB}$

Statistical expertise: NAB

Obtaining of funding: NAB

\section{Correspondence}

Dr Nurhidanatasha Abu Bakar

$\mathrm{PhD}$ (La Trobe University, Australia)

Lecturer and Researcher (Biomedicine Program)

School of Health Sciences,

Universiti Sains Malaysia,

1615o Kubang Kerian,

Kelantan, Malaysia.

Tel: +609 7677814

Fax: +609 7677515

E-mail: natashaa@usm.my/ nettynab79@yahoo.com

\section{References}

1. Alicata JE. Parasites of man and animals in Hawaii. Basel: Karger; 1969.

2. Centers for Disease Control and Prevention. About parasites. [Internet]. U.S.: Department of Health \& Human Services; 2016. [Retrieved 2018 Sep 5]. Available at: https://www.cdc.gov/ parasites/about.html

3. World Health Organization. World malaria report 2018. [Internet]. Geneva: World Health Organization; 2018 [Retrieved 2018 Dec 1]. Available at: https://www.who.int/malaria/ publications/world-malaria-report-2018/report/ en/

4. World Health Organization. World malaria report 2017. [Internet]. Geneva: World Health Organization; 2017. [Retrieved 2018 Jan 12]. Available at: https://www.who.int/malaria/ publications/world-malaria-report-2017/report/en/
5. Kerr K. Zoonoses: infectious diseases transmissible from animals to humans. $J$ Clin Pathol. 2004;57(10):1120. http://dx.doi. org/10.1136/jcp.2004.019646

6. Weiss LM. Zoonotic parasitic diseases: Emerging issues and problems. Int $J$ Parasitol. 2008;38(11):1209-1210. Available at: http:// www.ncbi.nlm.nih.gov/pubmed/18603251

7. Lu F, Huang S. The roles of mast cells in parasitic protozoan infections. Front Immunol. 2017;8:363. https://doi.org/10.3389/ fimmu.2017.00363

8. Wuerz $\mathrm{T}$, Kane JB, Boggild AK, Krajden $\mathrm{S}$, Keystone JS, Fuksa M, et al. A review of amoebic liver abscess for clinicians in a nonendemic setting. Can J Gastroenterol. 2012;26(10):729733. https://doi.org/10.1155/2012/852835

9. Alberts B, Johnson A, Lewis J, Raff M, Roberts K, Walter P. Molecular biology of the cell. 4th ed. New York: Garland Science; 2002.

10. Wink M. Medicinal plants: a source of antiparasitic secondary metabolites. Molecules. 2012;17(11):12771-12791. https://doi. org/10.3390/molecules171112771

11. Elsheikha HM. The future of parasitology: challenges and opportunities. Front Vet Sci. 2014;1:25. https://doi.org/10.3389/ fvets.2014.00025

12. Horn D, Duraisingh MT. Antiparasitic chemotherapy: from genomes to mechanisms. Annu Rev Pharmacol Toxicol. 2014;54:7194. https://doi.org/10.1146/annurevpharmtox-011613-135915

13. Mäser $\mathrm{P}$, Wittlin $\mathrm{S}$, Rottmann $\mathrm{M}$, Wenzler $\mathrm{T}$, Kaiser M, Brun R. Antiparasitic agents: new drugs on the horizon. Curr Opin Pharmacol. 2012;12(5):562-566. https://doi.org/10.1016/j. coph.2012.05.001

14. Mackey TK, Liang BA, Cuomo R, Hafen R, Brouwer KC, Lee DE. Emerging and reemerging neglected tropical diseases: a review of key characteristics, risk factors, and the policy and innovation environment. Clin Microbiol Rev. 2014;27(4):949-979. https://doi.org/10.1128/ CMR.00045-14 
15. Hertweck C. Natural products as source of therapeutics against parasitic diseases. Angew Chemie-Int Ed. 2015;54(49):14622-14624. https://doi.org/10.1002/anie.201509828

16. Kayser O, Kiderlen AF, Croft SL. Natural products as antiparasitic drugs. Parasitol Res. 2003;90(Suppl 2):S55-S62. https://doi.org/ 10.1007/soo436-002-0768-3

17. Achan J, Talisuna AO, Erhart A, Yeka A, Tibenderana JK, Baliraine FN, et al. Quinine, an old anti-malarial drug in a modern world: role in the treatment of malaria. Malar J. 2011;10:144. https://doi.org/10.1186/1475-2875-10-144

18. Guo Z. Artemisinin anti-malarial drugs in China. Acta Pharm Sin B. 2016;6(2):115-124. https://doi.org/10.1016/j.apsb.2016.01.008

19. Sofowora A, Ogunbodede E, Onayade A. The role and place of medicinal plants in the strategies for disease prevention. African $J$ Tradit Complement Altern Med. 2013;10(5):210-229. https://doi. org/10.4314/ajtcam.v10i5.2

20. Samuelsson G, Bohlin L. Drugs of natural origin: a textbook of pharmacognosy. 5 th ed. Stockholm: Swedish Pharmaceutical Press; 2004.

21. Jamal JA, Ghafar ZA, Husain K. Medicinal plants used for postnatal care in Malay traditional medicine in the Peninsular Malaysia. Pharmacogn J. 2011;3(24):15-24. https://doi. org/10.5530/pj.2011.24.4

22. Everest A, Ozturk E. Focusing on the ethnobotanical uses of plants in Mersin and Adana provinces (Turkey). J Ethnobiol Ethnomed. 2005;1:6. https://doi.org/10.1186/1746-4269-1-6

23. Sawangjaroen N, Sawangjaroen K. The effects of extracts from anti-diarrheic Thai medicinal plants on the in vitro growth of the intestinal protozoa parasite: Blastocystis hominis. $J \quad$ Ethnopharmacol. 2005;98(1-2):67-72. https://doi.org/10.1016/j.jep.2004.12.024

24. Umachigi S, Jayaveera K, Kumar CA, Swamy BV, Kumar DK. Studies on wound healing properties of Quercus infectoria. Trop $J$ Pharm Res. 2008;7(1):913-9. http://dx.doi.org/10.4314/tjpr. v7i1.14677
25. Sariozlu NY, Kivanc M. Gallnuts (Quercus infectoria Oliv. and Rhus chinensis Mill.) and their usage in health. Nuts Seeds Heal Dis Prev. 2011;505-511. https://doi.org/10.1016/B978-o12-375688-6.1006o-X

26. Hwang J, Kong T, Baek N, Pyun Y. a-Glycosidase inhibitory activity of hexagalloylglucose from the galls of Quercus infectoria. Planta Med. 2000;66(3):273-274. https://doi.org/ $10.1055 / \mathrm{s}-2000-8569$

27. Dar M, Ikram M. Studies on Quercus infectoria: isolation of syringic acid and determination of its central depressive activity. Planta Med. 1979;35(2):156-161. https://doi. org/10.1055/s-0028-1097197

28. Kaur G, Hamid H, Ali A, Alam M, Athar M. Antiinflammatory evaluation of alcoholic extract of galls of Quercus infectoria. J Ethnopharmacol. 2004;90(2-3):285-292. https://doi. org/10.1016/j.jep.2003.10.009

29. Basri DF, Tan LS, Shafiei Z, Zin NM. In vitro antibacterial activity of galls of Quercus infectoria Olivier against oral pathogens. Evidence-based Complement Altern Med. 2012:1-6. https:/doi. org/10.1155/2012/632796

30. Basri DF, Fan SH. The potential of aqueous and acetone extracts of galls of Quercus infectoria as antibacterial agents. Indian $J$ Pharmacol. 2005;37(1):26-29. https://doi. org/10.4103/0253-7613.13851

31. Voravuthikunchai S, Lortheeranuwat A, Jeeju W, Sririrak T, Phongpaichit S, Supawita T. Effective medicinal plants against enterohaemorrhagic Escherichia coli O157:H7. J Ethnopharmacol. 2004;94(1):49-54. https://doi.org/10.1016/j. jep.2004.03.036

32. Hussein G, Miyashiro H, Nakamura N, Hattori M, Kakiuchi N, Shimotohno K. Inhibitory effects of sudanese medicinal plant extracts on hepatitis C virus (HCV) protease. Phyther Res. 2000;14(7):510-516. https://doi. org/10.1002/1099-1573(200011)14:7<510::aidptr646>3.0.co;2-b

33. Baharuddin NS, Abdullah H, Abdul Wahab WN. Anti-Candida activity of Quercus infectoria gall extracts against Candida species. J Pharm Bioallied Sci. 2015;7(1):15-20. https://doi. org/10.4103/0975-7406.148742 
34. Tayel AA, El-Sedfy MA, Ibrahim AI, Moussa SH. Application of Quercus infectoria extract as a natural antimicrobial agent for chicken egg decontamination. Rev Argent Microbiol. 2018;50(4):391-397. https://doi.org/10.1016/j. ram.2017.12.003

35. Ozbilgin A, Durmuskahya C, Kilimcioglu AA, Kayalar H, Kurt O, Ermis VO, et al. In vitro efficacy of Quercus infectoria Oliv. and Achillea millefolium L. extracts against Blastocystis spp. isolates. Kafkas Univ Vet Fak Derg. 2013;19(3):511-516. https://doi.org/10.9775/ kvfd.2012.8196

36. Kheirandish F, Delfan B, Mahmoudvand H, Moradi N, Ezatpour B, Ebrahimzadeh F, et al. Antileishmanial, antioxidant, and cytotoxic activities of Quercus infectoria Olivier extract. Biomed Pharmacother. 2016;82:208-215. http://doi.org/10.1016/j.biopha.2016.04.040

37. Sawangjaroen N, Sawangjaroen K, Poonpanang P. Effects of Piper longum fruit, Piper sarmentosum root and Quercus infectoria nut gall on caecal amoebiasis in mice. $J$ Ethnopharmacol. 2004;91(2-3):357-36o. https://10.1016/j. jep.2004.01.014

38. Gray SB, Brady SM. Plant developmental responses to climate change. Dev Biol. [Internet]. 2016 Nov 1 [Retrieved 2019 Jan 21];419(1):6477. Available at: https://www.sciencedirect.com/ science/article/pii/Soo12160616302640

39. Ekor M. The growing use of herbal medicines: issues relating to adverse reactions and challenges in monitoring safety. Front Pharmacol. 2014;4:177. https://doi.org/10.3389/ fphar.2013.00177

40. Azwanida N. A Review on the extraction methods Use in medicinal plants, principle, strength and limitation. Med Aromat Plants. 2015;4(3):1-6. https://doi.org/10.4172/2167-0412.1000196

41. Kennedy DO, Wightman EL. Herbal extracts and phytochemicals: plant secondary metabolites and the enhancement of human brain function. $A d v$ Nutr. 2011;2(1):32-50. https://doi.org/10.3945/ an.110.000117

42. Demain AL, Fang A. The natural functions of secondary metabolites. Adv Biochem Eng Biotechnol. 2000;69:1-39. https://doi. org/10.1007/3-540-44964-7_1
43. Singh G, Kumar P. Extraction, gas chromatography-mass spectrometry analysis and screening of fruits of Terminalia chebula Retz. for its antimicrobial potential. Pharmacognosy Res. 2013;5(3):162-168. https://doi.org/ 10.4103/0974-8490.112421

44. Abdullah AR, Hapidin H, Abdullah $H$. The role of semipurified fractions isolated from Quercus infectoria on bone metabolism by using hFOB 1.19 Human Fetal Osteoblast cell model. Evidence-based Complement Altern Med. 2018:1-13. https://doi.org/10.1155/2018/5319528

45. Hajar EWI, Sulaiman AZ, Sakinah AMM. Assessment of heavy metals tolerance in leaves, stems and flowers of Stevia rebaudiana plant. Procedia Environ Sci. 2014;20:386-393. https://doi.org/10.1016/j.proenv.2014.03.049

46. Meyer B, Ferrigni N, Putnam J, Jacobsen L, Nichols D, McLaughlin J. Brine shrimp: a convenient general bioassay for active plant constituents. Planta Med. 1982;45(5):31-34. https://doi.org/10.1055/s-2007-971236

47. Katalinic V, Milos M, Kulisic T, Jukic M. Screening of 70 medicinal plant extracts for antioxidant capacity and total phenols. Food Chem. 2006;94(4):550-557. https://doi. org/10.1016/j.foodchem.2004.12.004

48. Thériault $M$, Caillet S, Kermasha S, Lacroix M. Antioxidant, antiradical and antimutagenic activities of phenolic compounds present in maple products. Food Chem. 2006;98(3):490-501. https://doi.org/10.1016/j.foodchem.2005.05.079

49. Ordaz-Pichardo C, Shibayama M, Villa-Treviño S, Arriaga-Alba M, Angeles E, de la Garza M. Antiamoebic and toxicity studies of a carbamic acid derivative and its therapeutic effect in a hamster model of hepatic amoebiasis. Antimicrob Agents Chemother. 2005;49(3):1160-1168. http://doi.org/10.1128/AAC.49.3.1160-1168.2005

50. Coyle CM, Varughese J, Weiss LM, Tanowitz HB. Blastocystis: to treat or not to treat. Clin Infect Dis. 2012;54(1):105-110. https://doi. org/10.1093/cid/cir810

51. Beyhan YE, Yilmaz H, Cengiz ZT, Ekici A. Clinical significance and prevalence of Blastocystis hominis in Van, Turkey. Saudi Med J. 2015;29;36(9):1118-1121. https://doi. org/10.15537/smj.2015.9.12444 
52. Voravuthikunchai SP, Chusri S, Suwalak S. Quercus infectoria. Oliv Pharm Biol. 2008;46(6):367-372. https://doi.org/10.1080/ 13880200802055784

53. Sundar S, Rai M. Laboratory diagnosis of visceral leishmaniasis. Clin Diagn Lab Immunol. 2002;9(5):951-958. https://doi.org/10.1128/ cdli.9.5.951-958.2002

54. De Muylder G, Vanhollebeke B, Caljon G, Wolfe AR, McKerrow J, Dujardin J-C. Naloxonazine, an amastigote-specific compound, affects Leishmania parasites through modulation of host-encoded functions. Satoskar AR, editor. PLoS Negl Trop Dis. 2016;10(12):eoo05234. http://dx.plos.org/ 10.1371/journal.pntd.ooo5234
55. Silva-Almeida M, Pereira BAS, Ribeiro-Guimarães $\mathrm{ML}$, Alves CR. Proteinases as virulence factors in Leishmania spp. infection in mammals. Parasit Vectors. 2012;5:160. https://doi.org/ 10.1186/1756-3305-5-160

56. Pigott DM, Bhatt S, Golding N, Duda KA, Battle KE, Brady OJ, et al. Global distribution maps of the leishmaniases. Elife. 2014;3:e02851. https://doi.org/10.7554/eLife.02851

57. Sifaoui I, López-Arencibia A, Martín-Navarro CM, Chammem N, Reyes-Batlle M, Mejri M, et al. Activity of olive leaf extracts against the promastigote stage of Leishmania species and their correlation with the antioxidant activity. Exp Parasitol. 2014;141:106-111. https://doi. org/10.1016/j.exppara.2014.03.002 